\title{
Pharmaceuticals in the Soil and Plant Environment: a Review
}

\author{
Barbara Gworek • Marta Kijeńska (1D) Justyna \\ Wrzosek • Magdalena Graniewska
}

Received: 6 July 2020 / Accepted: 6 December 2020 /Published online: 8 April 2021

(C) The Author(s) 2021

\begin{abstract}
Pharmaceuticals are a class of biologically active compounds used in human and veterinary medicine, while some of them may be applied for feed production and plant growth stimulation. To systemise the knowledge on pharmaceuticals in plant and soil environment, a literature review was performed. Active substances of pharmaceuticals and their metabolites are typically released into the environment through agricultural application of wastewater and sewage biosolids containing pharmaceuticals, derived from wastewater discharged by households, hospitals and other medical facilities. Another, no less important, source of pharmaceutical release are natural fertilisers (manure and slurry). The fate and behaviour of pharmaceuticals in the soil, including their mobility and availability to plants, depends on the soil physical, chemical and biological properties as well as on the properties of the substance itself. Pharmaceuticals introduced into the soil are taken up and retained in various plant parts. In general, the highest accumulation coefficients have been found in vegetative plant parts, in the following decreasing order: roots $>$ leaves $>$ stems, while the lowest in generative parts, such as grains of cereals.
\end{abstract}

Keywords Pharmaceuticals · Environment · Soil · Plants · Accumulation · Antibiotics

B. Gworek · M. Kijeńska $(\bowtie) \cdot J$. Wrzosek •

M. Graniewska

Institute of Environmental Protection - National Research

Institute, Krucza 5/11 d, Warsaw, Poland

e-mail: marta.kijenska@ios.edu.pl

\section{Introduction}

Pharmaceuticals are biologically active substances used in both human and veterinary medicine. Primarily, they are applied for therapeutic and preventive purposes, but not solely, since they are widely used in animal husbandry and food production, and as the so-called growth stimulants. In the past, the antibiotic growth stimulants, now banned from using, and other veterinary medicines, were commonly applied for breeding purposes. This was because the priority was to ensure the increased gain of live weight, while totally neglecting the issues of food quality as well as safety of raw materials and food items of animal origin. The problem has already gained a global dimension, and currently, in accordance with the regulations of the European Commission (Council Directive 96/23/EC and Commission Decision 93/256 /EEC), the food quality should be controlled by the Member States. Additionally, all Member States were required to withdraw, as of January 1, 2006, the feed additive antibiotic growth stimulants, used before that date, and to confine usage uniquely to the approved substances, for which the States were also obliged to carry out control activities (Balizs and Hewitt 2003; Botsoglou 2001; Kemper 2008; Nollet 2004).

The pharmaceutical industry, while advancing the science and developing research technologies, has achieved many benefits in the field of pharmaceutical protection of health and life of people and animals. However, when talking about the achievements in the field of pharmacotherapy, one should also consider the numerous still unresolved problems with residues of 
pharmaceutical active substances present in the environment and food (Jjemba 2006). International institutions predict that the consumption of drugs in the coming years will increase due to a wider access to lessexpensive medicines, including the generic ones, as well as due to the introduction of advanced technological solutions. The average consumption of some groups of medicines, such as diabetes medications, increased by as much as 75\% between 2000 and 2009 (OECD 2011), and further growth is forecasted. According to the QuintilesIMS Institute report, the average annual growth in value (CAGR 2016-2020) of the global pharmaceutical market will reach a rate of 4-7\% (Quintiles IMS 2016).

Generally, there have been identified three major sources ("point" and disperse "non-point" ones) of releasing pharmaceuticals and their metabolites into the environment. The major "point" source of emitting drug active substances is the pharmaceutical industry, from which they are released during drug production. As a result of inappropriate management of drug-containing waste from industries, hospitals or households, these substances are discharged into the environment without any treatment. Another source of release of pharmaceutical active substances into the environment, classified as a disperse source, is wastewater and sewage sludge from municipal wastewater treatment plants. Wastewater is the source of drugs excreted by humans not only in households but also in hospitals and other therapeutic facilities. Widespread application of effluents and biosolids for fertilising purposes contributes to the release of significant amounts of pharmaceuticals into the environment.

For example, such substances as, among others, fluoroquinolones, ciprofloxacin and norfloxacin, which are not degraded in the wastewater treatment process, accumulate in significant quantities in sewage sludge (Hamscher et al. 2001). The third source which releases the compounds in question into the environment, also classified as a disperse source, is soil fertilisation with organic fertilisers, including manure and slurry, or with other natural fertilisers containing animal excreta. According to estimates, the release of pharmaceutical active substances into the environment due to the use of veterinary medicines is many times higher than that resulting from the human drug application. That is why, it is widely recognised that the impact of veterinary drugs on soil and groundwater is much greater than on the surface water pollution (Balizs and Hewitt 2003;
Halling-Sørensen et al. 1998; Heberer 2002; Kümmerer 2004; Reemtsma and Jekel 2006; Sacher et al. 2001; Sarmah et al. 2006). For example, it is estimated that the load of antibiotics entering the soil with natural fertilisers attains the level of several kilograms per hectare. The concentrations of antibiotics determined in this load often exceed $400 \mathrm{mg} / \mathrm{kg}$ of soil, with the highest proportions of antibiotics from the tetracycline group, often used in pig breeding (Kemper 2008).

Another source of pollutants is the usage of reclaimed water for irrigation purposes in recreational areas, e.g. golf courses (Salgot et al. 2012). In the study of Calderon-Preciado et al. (2011), it was proven that the reclaimed water may be a source of pollutants which can be further included into the biological chain by their uptake by plants.

Based on their works, Boxall (2004) and Monteiro and Boxall (2010) emphasise that active ingredients of pharmaceuticals can enter the soil environment when the residue loaded sewage sludge and outflows from sewage treatment plants or fertilisers of animal origin are applied onto the soil surface, e.g. for fertilisation purposes (Boxall 2004; Monteiro and Boxall 2010). Moreover, Hamscher et al. (2001) and Heberer (2002) have shown that veterinary pharmaceuticals enter the soil mainly due to the use of manure as a fertiliser or with excrements of farm animals, or as a result of introducing sewage sludge into the soil for fertilising purposes (Hamscher et al. 2001; Heberer 2002).

Population growth, increased wealth and greater access to medicines have led to an increase in the load of pharmaceutical active ingredients entering the sewerage system. In the areas where land is irrigated with treated, partially treated or untreated effluents and sewage biosolids are introduced, some amounts of pharmaceuticals may accumulate in the soil. Wastewater used for irrigation is currently not covered by chemical standards, including environmental risk assessment. Pharmaceuticals can be degraded during the biological treatment of wastewater as well as in water bodies, in soils, and in the course of abiotic reactions. These processes reduce the potentially harmful effects of drugs; however, some products of their breakdown have similar toxicity as the parent substance (Halling-Sörensen et al. 2002).

The fate and behaviour of pharmaceuticals in soils depends on their biological, chemical and physical properties. Depending on the physicochemical properties of pharmaceuticals and soil properties, these substances can either be retained in the topsoil or leached into 
groundwater and flow towards surface water (Davis et al. 2006; Doruk et al. 2018; Jałowiecki et al. 2019; Yang et al. 2012). They can also be taken from the soil by plants (Kumar et al. 2005; Shenker et al. 2011a; Wu et al. 2010).

\section{Occurrence, Transport and Transformation of Pharmaceuticals in the Soil}

The migration of pollutants down into the soil profile depends on the intensity of their sorption on the soil solid phase particles. The sorption intensity affects the bioavailability of active substances of medicines and their persistence in the soil environment. Therefore, the soil sorption capacity plays an important role in the exposure of living organisms to contamination. Kodešová et al. (2016) examined the dispersion of selected active substances of pharmaceuticals from such groups as antibiotics (trimethoprim, sulfamethoxazole, clindamycin and clarithromycin); beta-blockers (atenolol and metroprolol) and psychotropic drugs (carbamazepine) in 13 different soil types. The halflife of the drugs was related to the soil properties. Among the abovementioned substances, carbamazepine was shown to have the highest persistence in the soil, followed by clarithromycin, trimethoprim, metroprolol, clindamycin, sulfamethoxazole and atenolol. The halflife reflects the sorption process of the pharmaceuticals on the soil particles and increases with the increase in the soil sorption capacity. In several cases (atenolol, metropropolol and trimethoprim), the half-life decreased with the increase in sorption capacity of soil (Kodešová et al. 2016). The study results indicate that durability of pharmaceuticals in the soil depends mainly on the soil type. A lower average half-life for the tested compounds was found in more fertile soils (e.g. chernozem) with a good structure, a high content of organic matter and a high biological activity (Kodešová et al. 2016).

Borgman and Chefetz (2013) conducted a study to elucidate the combined effects of applying biosolids and irrigating with reclaimed effluents on the mobility of selected pharmaceuticals in soils, and to attempt to elucidate the main mechanisms affecting leaching of pharmaceuticals. Column-leaching experiments showed that application of fertilisers generally increased the retardation of the process of pharmaceutical leaching, whereas the treated effluents increased the mobility of weakly acidic pharmaceuticals in the biosolid-amended soils. The studies conducted at the environmentally relevant pharmaceutical concentrations ( $1 \mu \mathrm{g} / \mathrm{L})$ highlight the importance of irreversible sorption as a possible mechanism for low leaching capacity. The research results suggest that:

- Migration of pharmaceuticals in arable soils may be forced by the frequent use of biosolids.

- Treated effluents increase the mobility of weakly acidic pharmaceuticals, due mainly to the increase of the soil solution $\mathrm{pH}$, and not due to the complexation reaction of pharmaceuticals with dissolved organic matter.

- In order to reliably assess the movement of pharmaceuticals in the environment, it is very important to rely on real values occurring in the environment and not on the data obtained from model experiments carried out at high concentrations (Borgman and Chefetz 2013).

The impact of soil reaction, clay content and organic matter on the fate of organic compounds susceptible to ionisation has been discussed in detail in Lees et al. (2016). The concentration of selected pharmaceuticals determined in soils in different countries is illustrated in Table 1.

\subsection{Sorption and Biodegradation of Pharmaceuticals in the Soil Environment}

Soil sorption properties are of major significance for determining the fate and behaviour of pharmaceuticals in soils due to the mechanisms of their migration and degradation processes. Yu et al. (2013) studied the sorption and degradation processes of carbamazepine, gemfibrozil, octylphenol, triclosan and bisphenol Aw in three different soils. The adsorption isotherms of all the pharmaceuticals in the soil were described using the Freundlich eq. A moderate or strong sorption was determined for triclosan and octylphenol, whereas the sorption of gemfibrozil and carbamazepine was negligible. The half-life of pharmaceuticals in the soil ranged from 9.8 to 39.1 days (Yu et al. 2013). The protracted half-life of pharmaceuticals in sterile soils suggests that microbiological activity played an important role in the degradation of these compounds. The degradation was also affected by the content of soil organic carbon. Poor sorption and high persistence of carbamazepine in the 
Table 1 The concentration of selected pharmaceuticals in soils in different countries (ng/g)

\begin{tabular}{|c|c|c|c|c|}
\hline Substance & Country & $\begin{array}{l}\text { Measured } \\
\text { concentrations } \\
{[\mathrm{ng} / \mathrm{g}]}\end{array}$ & $\begin{array}{l}\text { Average integrated pharmaceutical masses (total ng) } \\
\text { in soils normalized to soil organic carbon content }\end{array}$ & References \\
\hline Triclocarban & China & $0.3-51.8$ & - & \multirow[t]{4}{*}{ Chen et al. (2011) } \\
\hline Salicylic acid & China & $1.0-7.3$ & - & \\
\hline Oxytetracycline & China & $3.3-139$ & - & \\
\hline Tetracycline & China & $1.9-17.4$ & - & \\
\hline Acetaminophen & USA & - & $5.42-33.2$ & \multirow[t]{6}{*}{ Kinney et al. (2006) } \\
\hline Trimethoprim & USA & - & $1.22-2.22$ & \\
\hline Warfarin & USA & - & $4.48-23.9$ & \\
\hline Sulfamethoxazole & USA & - & $9.13-42.6$ & \\
\hline Erythromycin & USA & - & $108.3-210$ & \\
\hline Carbamazepine & USA & - & $16.9-23.5$ & \\
\hline Doxycycline & Malaysia & $62.6-728.4$ & - & \multirow[t]{4}{*}{ Ho et al. (2012) } \\
\hline Norfloxacin & Malaysia & $<$ MQL-95.7 & - & \\
\hline Trimethoprim & Malaysia & $<$ MQL-60.1 & - & \\
\hline Progesteron & Malaysia & $<$ MQL-24.2 & - & \\
\hline Acetaminophen & Spain & n.d.-5.95 & - & \multirow[t]{5}{*}{ Biel-Maeso et al. (2018) } \\
\hline Diclofenac & Spain & n.d.-5.06 & - & \\
\hline Carbamazepine & Spain & $0.08-1.36$ & - & \\
\hline Flumequine & Spain & n.d.-5.31 & - & \\
\hline Hydrochlorothiazide & Spain & $0.38-1.20$ & - & \\
\hline
\end{tabular}

soil offer an indication that the chemical may pose a risk of leaching to groundwater when land is irrigated with untreated sewage.

The results of the study by Lin and Gan (2011) also demonstrate that the rate of pharmaceuticals degradation is affected by the presence of microorganisms and aerobic conditions in the soil, by soil type and properties of the pharmaceutical itself. The research was conducted on the soil material originating from arid regions: clay sands were sampled from Boulder City in Nevada and from the North Las Vegas. To assess the environmental risks for these soils, they were irrigated with the contaminated recycled water, and the processes of sorption and degradation were investigated for five pharmaceuticals which were antibiotics and anti-inflammatory drugs. Naproxen and trimethoprim showed moderate to strong sorption, while the sorption of diclofenac, ibuprofen and sulfamethoxazole in both soils was negligible, which increased their mobility in the soils and could cause their leaching into groundwater. Under aerobic conditions, the tested compounds were susceptible to microbial degradation with half-lives varying from 4.8 to 69.3 days. Apart from sulfamethoxazole, all the substances examined were highly persistent in the soil under anaerobic conditions with a half-life $>50$ days (Lin and Gan 2011).

Monteiro and Boxall (2009) conducted a study to assess the effects of soil type and the impact of biosolids with the addition of a mixture of pharmaceuticals (with an addition of antibiotic sulfamethazine) on the degradation of naproxen, carbamazepine and fluoxetine. The study showed that naproxen degraded in an array of soils with half-lives ranging from 3.1 to 6.9 days, and in biosolids with a half-life of 10.2 days. No correlation was observed between degradation rate and soil physicochemical and biological properties. The addition of biosolids to soils reduced the degradation rate of naproxen. The half-life of the drug in the fertilised soil ranged from 3.9 to 15.1 days. Carbamazepine and fluoxetine were found to be persistent in soils, biosolids and in soil fertilised with biosolids. When the degradation was assessed using a mixture of the three study compounds with the addition of an antibiotic, the degradation behaviour of fluoxetine and carbamazepine was similar to that observed in the single-compound studies, i.e. there was no degradation. The degradation rate of naproxen in soils, biosolids, and biosolid fertilised soils was significantly slower following the 
application of pharmaceutical mixture than in the singlecompound study (Monteiro and Boxall 2009). Due to the fact that pharmaceuticals in the aquatic environment occur as mixtures, an accurate prediction of the mixture toxicity is necessary for ecotoxicological risk assessment (Cleuvers 2004).

Drillia et al. investigated the sorption process and mobility of six pharmaceuticals, including carbamazepine, propanolol, diclofenac, clofibric acid, sulfamethoxazole and ophaxacin, in two soil types varying in the content of organic carbon, clay particles and bacterial biomass (under aerobic and anaerobic conditions). The sorption tests were carried out in accordance with the OECD method No. 106: Adsorption-Desorption determination of equilibrium. When comparing the results of the abovementioned tests, it can be noticed that the mobility of pharmaceuticals in the soil correlates with their sorption properties. Ofloxacin was absorbed most powerfully, while clofibric acid was poorly adsorbed, what was the reason behind its presence in the leacheate. The fate and behaviour of active substances of pharmaceuticals in the soil were also examined using a lysimeter. It was shown that the mobility of these compounds in the soil and, consequently, potential groundwater contamination, depends on their concentration in the environment, on the intensity of precipitation and the soil type (Drillia et al. 2005).

The adsorption and biodegradation behaviour of the following antidiabetic drugs: glimepiride, glibenclamide, gliclazide and metformin in three soil types were investigated by Mrozik and Stefańska (2014). The sorption of sulphonylurea derivatives, on which three out of the above drugs were based, was high, while metformin showed a high mobility in the soil. The retention of the drugs examined was determined by the type of soil and its physicochemical properties. The rate of the desorption process, the process opposite to sorption, was highest for metformin, which has a low affinity to the solid phase of the soil. A low solubility and strong affinity of the medicines for organic matter suggests that they can be highly immobile in environmental matrices. Their biodegradation and transformation is strongly adversely affected by the intensive sorption. In this study, the transformation processes were mainly observed under aerobic conditions. The results demonstrated that the metformin biodegradation was much more intensive than that of the three other drugs (Mrozik and Stefańska 2014).
Ketoprofen, which belongs to non-steroidal anti-inflammatory drugs, is not strongly adsorbed in the soil, which may facilitate its leaching, provided the water activity is in place. In a study carried out by $\mathrm{Xu}$ et al. (2009) using four US soil types, including loamy sand from Arlington (ASL), sandy loam from Hanford (HLS), silty clay from Imperial (ISC) and silt loam from Palouse (PSL), ketoprofen was degraded mainly by soil microorganisms. A higher persistence of ketoprofen in soils rich in organic matter may be attributed to reduced availability of the compound due to the increased adsorption in this soil type. The ketoprofen half-life was longest for silt loam and shortest for loamy sand (Table 2), which clearly indicates the relationship between the sorption capacity of soils and the half-life of the compound examined.

The environmental risk was assessed in China for levonorgestrel, an artificial progesterone, used as an active ingredient in hormonal contraception. The laboratory experiment using the soil microcosm was performed in order to understand the degree of adsorption and biodegradation of the artificial hormone in five different types of soils. The half-life of levonorgestrel ranged from 4.32 to 11.55 days. There was no degradation of the tested hormone in the sterile soil during the 120-day-long incubation. This suggests that microbial transformations dominated the overall distribution of levonorgestrel in the soil. The results of the study have shown that levonorgestrel can be strongly absorbed in arable soils and pastures. The dominant mechanism of sorption seems to be the binding of levonorgestrel by organic carbon (TOC - total organic carbon) (Tang et al. 2012).

Pharmaceutical active substances have been introduced into cultivated soils through irrigation using treated wastewater. Grossberger et al. (2014) showed that non-ionic drugs, such as carbamazepine, lamotrigine,

Table 2 The half-lives $\left(t_{1 / 2}\right)$ of ketoprofen in soils (according to $\mathrm{Xu}$ et al. 2009)

\begin{tabular}{lll}
\hline Soil* $*$ & $\begin{array}{l}\text { Organic matter content in soil } \\
{[\%]}\end{array}$ & $\begin{array}{l}\text { The half-lives }\left(t_{1 / 2}\right) \\
(\text { days })\end{array}$ \\
\hline ASL & 0.58 & 4.58 \\
HLS & 1.93 & 8.04 \\
ISC & 2.46 & 15.37 \\
PSL & 5.45 & 27.61
\end{tabular}

*Author designations 
metoprolol, sulfamethoxazole and sildenafil, were resistant to breakdown and accumulated in the soil following the irrigation with treated wastewater containing residues of the drugs. However, other pharmaceuticals, including diclofenac, ibuprofen, bezafibrate, gemfibrozil and naproxen, were not detected in the same soil, which was most likely due to their rapid degradation.

In the USA, the biological degradation rates of selected pharmaceuticals and personal care products were examined in the soil with a high water content. Microbial degradation rates were compared over 2 weeks under standing water or saturated conditions and draining conditions after having been saturated for 3 days (Table 3). 17 $\beta$-estradiol exhibited rapid rates of biological degradation under both saturated and draining conditions; however, the rate of biodegradation for most of the analysed substances was much faster under dehydrated conditions. The high soil water content was observed to have a significant impact on the inhibition of microbiological processes of pharmaceuticals degradation. An interesting observation in this study was that the degradation rate under draining conditions was apparently faster after the third day, when the soil was close to reaching its field capacity, after draining the excess water (Carr et al. 2011).

Dalkmann et al. (2014) studied soils irrigated with untreated wastewater at various times, sampled in the Mezquital Valley in Mexico. The study was made using soils not irrigated with wastewater, soils irrigated for 14 years and those irrigated for 100 years. It has been shown that long-term irrigation with untreated wastewater can increase the adaptation of soil microorganisms in relation to the contamination load. A hypothesis has been put forward that long-term soil irrigation with untreated wastewater accelerates the breakdown of

Table 3 The half-lives $\left(t_{1 / 2}\right)$ of selected pharmaceuticals in the conditions of soil saturation with water and drained (according to Carr et al. 2011)

\begin{tabular}{lll}
\hline Substance & \multicolumn{2}{l}{ The half-lives $\left(t_{1 / 2}\right)$ (days) } \\
\cline { 2 - 3 } & Saturated conditions & Draining conditions \\
\hline 17ß-estradiol & $1.5-3.4$ & $2.6-4$ \\
Triklosan & 400 & 70.9 \\
Ibuprofen & $707-1706$ & $30.4-34.3$ \\
Estriol & $15.6-25.9$ & $8.7-11.9$ \\
Estron & $38.1-56.8$ & $27.5-33.4$ \\
\hline
\end{tabular}

pharmaceuticals. Thus, the half-life of diclofenac was $<0.1-1.4$ days, followed by bezafibrate $<0.1-4.8$ days, and sulphamethoxazole - from 2 to 33 days, while the naproxen half-life was in the range of 6-19 days and that of carbamazepine from 355 to 1624 days. Degradation of trimethoprim was slower in the soil irrigated for 100 years (45-72 days) than in the non-irrigated soil (12-16 days) and was correlated with the content of soil organic matter and the coefficient of soil water distribution. It was found that microbiological processes play a less significant role in the degradation of pharmaceuticals in soils irrigated with wastewater, and the accumulation of organic matter in these soils may slow down the degradation of trimethoprim and carbamazepine.

Adsorption of pharmaceuticals in sewage sludge depends on both their hydrophobic properties and electrostatic interactions with sediment particles and on the activity of microorganisms. The acidic compounds including acetylsalicylic acid, ibuprofen, ketoprofen, naproxen and diclofenac as well as indomethacin with the pKa values from 4.9 to 4.1 , similarly as clofibrilic acid and bezafibrate (pKa 3.6), occur in ionic forms under neutral $\mathrm{pH}$, and have a slight tendency to adsorb on sewage sludge. However, the adsorption of these drugs in the sludge increases at lower $\mathrm{pH}$ values. Under a neutral $\mathrm{pH}$, pharmaceutical compounds with negative charge reside mainly in the dissolved phase of wastewater (Fent et al. 2006). In the digested sewage sludge, there is usually no adsorption of pharmaceuticals or it remains relatively low. However, when sewage sludge is used as a fertiliser, there is a potential for passing the easily adsorbable pharmaceutical compounds into the environment (Nikolaou et al. 2007).

Giger et al. (2003) concluded that the highest contents of fluoroquinolones may be found in sewage sludge. According to Giger et al. (2003), $80-90 \%$ of fluoroquinolones, ciprofloxacin and norfloxacin is eliminated from the treated wastewater mainly owing to the sorption on sewage sludge. The content of fluoroquinolones in the processed sludges may be of the order of $\mathrm{mg} / \mathrm{kg}$. In view of the ever increasing use of manure and sewage sludge for fertilising arable fields, fluoroquinolones are transported to the soil, where they build up and may have detrimental effect on organisms. The source of fluoroquinolones in the soil may be either irrigation of arable fields with water coming from wastewater treatment plants or leaks from sewerage systems. The persistence of these compounds in the soil depends mainly on their photostability, capacity for adsorption 
and formation of bonds with soil particles, their breakdown rate and rate of leaching to groundwater (Picó and Andreu 2007).

Aerobic and anaerobic degradation are processes of major significance for removal of pharmaceuticals during wastewater treatment. The amount of removed compounds depends on retention time and age of sewage sludge, and increases along with the hydraulic retention time. For example, biodegradation of diclofenac in sewage sludge occurs only after 8 days of sludge retention (Fent et al. 2006).

\subsection{Antibiotics in the Soil}

Antibiotics are highly effective, bioactive substances used in human and veterinary medicine, as well as in aquaculture for the prevention or treatment of bacterial infections. Some antibiotics are also used in orchards and in beekeeping. As a result of their consumption, excretion and a high persistence, they have been widely spread in the soil environment, mainly through the common application to arable lands of biosolids originating from municipal wastewater treatment plants.

Substances entering the environment may undergo various reactions resulting from partial or complete degradation, i.e. mineralisation of the parent compound. Based on the degradation process, antibiotics can be divided into the following groups:

- Antibiotics and their metabolites, which are mineralised by microorganisms and therefore completely eliminated from circulation

- Partially degraded antibiotics

- Hardly degradable antibiotics, which persist in the environment

The elimination processes can be either biotic or abiotic (e.g. adsorption, mineralisation, hydrolysis, photolysis, thermolysis, redox reaction). Biological degradation plays a key role in the environment, though elimination through hydrolytic and photochemical reactions also takes place (Alexy 2001).

Antibiotics in the soil may also originate from natural processes, e.g. tetracycline is produced by the bacteria that occur naturally in the soil. The dynamics of microbial populations in the soil is also affected by the resistance to these antibiotics. (Kümmerer 2001) reports that no presence of tetracycline was traced in the soil that was not fertilised with manure. In general, the biodegradation in the soil of substances from various groups of antibiotics, such as virginiamycin, tetracycline, oxytetracycline, chlorotetracycline and cyclosporine A, was slow. Tylosin was degraded just following the application of manure. Laboratory tests have shown that enrofloxacin was degraded by white fungal roots that may be present in the soil; however, they do not occur in sewage sludge (Kümmerer 2001). The adsorption of antibiotics on mineral and organic parts of soils was mainly caused by the transfer of charge and ionic interactions. The sorption process is significantly influenced by the medium $\mathrm{pH}$. The studies have shown that the migration process of the highly absorbed antibiotics deep into the soil is fast owing to the presence of macropores (Thiele-Bruhn 2003).

There are very few studies on the content of antibiotics in soils; usually they are persistent and capable of building up in the environment. According to the studies carried out so far, particular classes of veterinary antibiotics reach different maximum contents in the test soils due to manure application. These contents are very low compared to the content of these compounds in manure (concentration of the order of hundredth parts [mg/kg] for tetracycline and of thousandths parts for sulfonamides and macrolides).

Tetracyclines are easily accumulated in the soil due to their slow degradation in the environment. In the soil solution, their behaviour differs from that of sulphonamides, since they reach concentrations up to $150 \mu \mathrm{g} / \mathrm{kg}$ of soil, which is twice as high as quoted for sulfonamides. Tetracyclines are strongly sorbed in the soil surface layers and do not migrate deep into the soil profile and into groundwater, as opposed to sulfonamides, some of which have been traced in groundwater. The reason behind the elevated levels of antibiotics occurring locally in the soil solution is the formation on the soil surface of manure aggregates with a high concentration of individual antibiotics. The mobility of antibiotics in the soil depends on the soil type and, e.g., sulphachloropyridazine remains mobile in sandy soils, as opposed to loamy soils (Hamscher et al. 2001). The main source releasing antibiotics to the environment is sewage sludge introduced into soils for fertilising purposes. Substances that are not subject to degradation during wastewater treatment accumulate in sludges in significant quantities. The studies have shown the presence of fluoroquinolones, ciprofloxacin and norfloxacin in sludges in concentrations from 1.4 to $2.4 \mathrm{mg} / \mathrm{kg}$ of the sludge dry matter. Fluoroquinolones 
proved to be stable in soils fertilised with sludges for about 2 years (at a concentration of about $0.3 \mathrm{mg} / \mathrm{kg}$ of soil) (Hamscher et al. 2001). Antibiotics may also enter the soil, albeit in small quantities, from the air deposition of the finest dust particles as carriers of these compounds (Hamscher et al. 2001).

\section{Ecotoxicology}

There is little information on the bioaccumulation of pharmaceuticals in organisms or in the trophic chain. In livers of fishes, the diclofenac bioaccumulation coefficient was 10-2700 while in their kidneys 5-1000 (Czech 2012). Compounds such as fluoxetine, sertraline, and norfluoxetinidemethylsertraline have also been detected in fish tissue (Nikolaou et al. 2007).

The high sorption coefficient of tetracycline antibiotics and fluoroquinolones in the soil solution results in their low bioavailability. The effect of antibiotics contained in the soil solution on higher organisms is relatively unlikely, and has not so far been discussed in the literature. For example, according to the studies conducted up to now, oxytetracycline and, e.g., tylosin (used in veterinary medicine) entering the soil have no effect on the soil organisms, such as earthworms, collembols and enchytraeids (Hamscher et al. 2001).

Another issue is development of anti-microbial resistance (AMR). The development of AMR is of particular concern with regard to human and animal health and has received considerable attention in the last few yearsincluding AMR arising from pharmaceuticals in the environment (Deloitte for EC 2015). Some information on AMR in soil and manure is presented in Table 4.

There are very few papers regarding the ecotoxicology of pharmaceuticals in the soil environment. The effects on the aquatic environment are much better investigated (Gworek et al. 2019; Gworek et al. 2020; Pal et al. 2013). Among the most toxic substances for aquatic species are antibiotics, especially neomycin, trimethoprim, sulfamethoxazole and enrofloxacin (Gworek et al. 2019).

Substances that are incompletely or completely removed during wastewater treatment and may enter into groundwater can also affect aquatic organisms at different trophic levels. The results of ecotoxicity tests using bacteria indicate that these compounds may have a significant adverse effect on natural bacterial populations, e.g. it was shown that tetracycline exposure led to inhibitory chronic impacts on the growth of nitrifying bacteria (Katipoglu-Yazan et al. 2015).

Algae show varying sensitivity to antibiotics. Selenastrum capricornutum is much less sensitive to antibiotics than Microcystis aeruginosa. Cyanobacteria are sensitive to most antibiotics, e.g. to amoxicillin, benzyl penicillin, sarafloxacin, spiramycin, tetracycline and tiamulin. Many plant species are susceptible to antibiotics which can affect the replication of chloroplasts (fluoroquinolones), transcription and translation (tetracyclines, macrolides, lincosamides, $\beta$-aminoglycosides), metabolic pathways of biosynthesis (sulphonamides) and fatty acid synthesis (triclosan). Antibiotics in the aquatic environment may also adversely affect reproduction and the initial development stages of aquatic organisms, which translates into a threat to entire populations.

\section{Pharmaceuticals in Plants}

Growing plants on substrates containing pharmaceuticals may have an impact on their development (FattaKassinos et al. 2011). It is not clear whether the negative effect on plants results from a direct damage to plants caused by the pharmaceuticals themselves, or whether their antibacterial activity on soil microorganisms is responsible for damage via affecting the symbiosis of a plant with the soil bacteria (Grassi et al. 2013).

Antibiotics in the soil can affect plant growth by disrupting the biological balance. The reason for this disturbance is most probably the breakdown of a large number of soil bacteria, which leads to a lack of food for soil fauna (micro-worms, nematodes, protozoa), and subsequently influences the processes occurring in the soil. Due to the slower decomposition of plant residues, the denitrification process is decelerated; therefore, nutrients are processed more slowly, and consequently, are harder to access for soil organisms (Fatta-Kassinos et al. 2011). Moreover, some studies have shown that both the toxic effect and the phenomenon of hormesis may affect the effectiveness of drug uptake by plants (of the order of $\mathrm{mg} / \mathrm{kg}$ ) (Grassi et al. 2013).

Mobility and bioavailability of pharmaceuticals to plants varies between the cultivation in the soil and in the hydroponic system, and also depends on soil properties, including organic carbon content and ion exchange capacity (Carvalho et al. 2014). 
Table 4 AMR in soil and manure (according to Deloitte for EC 2017)

\begin{tabular}{lll}
\hline Compartment & AMR genes & Reference \\
\hline Manure and non-amended soils & $\beta$-lactam anti-microbial resistant genes & Graham (2016) \\
Soils, cattle and farm environment & Beta-lactamase resistant genes & Hartmann (2013) \\
Manure and amended soils & Sulfadiazine and sulphonamide resistance & Heuer (2011) \\
\hline
\end{tabular}

\subsection{Accumulation of Pharmaceuticals in Plants}

Many different active substances of pharmaceuticals, which are present in biosolids produced mainly from municipal sludge, whose agricultural use may cause contamination of soils as well as of surface and groundwater, may often lead to the accumulation of these substances in plants. For the assessing of the accumulation of different substances in organisms, we use the bioaccumulation factor. Bioaccumulation, according to the EPA definition, is the net uptake of a pollutant from the environment. Bioaccumulation factors (BAF) are calculated by considering pollutant tissue concentrations with respect to environmental pollutant concentrations. BAF values $>1$ indicate that the accumulation in the organism is greater than that of the medium (e.g. soil or water) from which the pollutant was taken. These factors can be calculated on a total organism basis or normalized to the lipid content of the organism.

Eggen et al. (2011), considering the fact that sewage sludge and manure are a potential source of bioactive substances, such as medicines used in human and veterinary treatment, examined the absorption of metformin (an antidiabetic medicine), ciprofloxacin (antibiotic) and narasin (coccidiostat) in carrot (Daucus carota ssp. sativus cv. Napoli) and barley (Hordeum vulgare). It was shown that the bioaccumulation coefficients of ciprofloxacin and narasin in all the analysed plant parts were below 1 .

Metformin traced in sewage sludge, in a concentration of $0.5-1.6 \mathrm{mg} / \mathrm{kg}$ dry weight., generally showed a higher coefficient of bioaccumulation in the roots (210) than in the leaves $(0.1-1.5)$. It was observed that the bioaccumulation factor in turnip seeds was above 1 and was 40-60 times higher than that in barley or wheat seeds. The mechanism of a greater affinity for the accumulation of pharmaceuticals by oilseeds should be explored in more detail. The uptake of antibiotics used in veterinary medicine by plants grown on soils fertilised with manure and the consumption of these plants by humans poses a potential risk of exposure to residues of active drug substances, in particular of chlortetracylines (Halling-Sørensen et al. 1998; Kümmerer 2009).

The pharmaceuticals introduced into the soil have a tendency to accumulate there for a longer time period. Some pharmaceuticals can be taken up by plants and then they can accumulate in various plant tissues, e.g. uptake of chlortetracycline by carrots results in accumulation of this compound in roots while the uptake by lettuce and corn results in the accumulation of the pollutant in leaves. The concentrations of chlortetracycline and sulfamethazine in plant tissues were low (2$17 \mu \mathrm{g} / \mathrm{kg}$ ); however, these concentrations increased in proportion to their concentrations in manure used as fertiliser (Al-Farsi et al. 2017). The highest concentrations of these compounds have been described in the tissues of maize, lettuce and potatoes. Diazinon, enrofloxacin, florfenicol and trimethoprim accumulated also in leaves of lettuce, while florfenicol, levamisol and trimethoprim in carrot roots (Boxall et al. 2006); according to the author, the results of research carried out so far show a low risk of exposure to these substances through the consumption of vegetables. However, the risk may be important in the case of compounds whose daily acceptable dose is very low, or those that produce subtle effects over a longer period of time, or when their consumption occurs from various sources simultaneously (Kümmerer 2009).

In the USA, the accumulation of three antibiotics (sulfamethoxazole, trimethoprim and ofloxacin) and an antiepileptic medicine (carbamazepine) was studied in common wheat (Triticum aestivum L.) grown on soil watered with treated wastewater from sewage treatment plants. The wheat after harvest was divided into grain and straw. The sub-samples were rinsed with methanol to remove chemical compounds from the surface. All parts of plants were extracted in the liquid-solid system and in the solid phase by LC-MS. Residues of each compound were present on most plant surfaces. Ofloxacin was found at high concentration in straw $(10.2 \pm 7.05 \mathrm{ng} / \mathrm{g})$, with lower concentration in grain $(2.28 \pm 0.89 \mathrm{ng} / \mathrm{g})$. Trimethoprim was determined only 
on the surface of grain and straw, while carbamazepine and sulfamethoxazole were determined only in cereal grains (respectively $1.88 \pm 2.11$ and $0.64 \pm 0.37 \mathrm{ng} / \mathrm{g}$ ). Studies have shown that pharmaceuticals can be taken up by plants and accumulated in various plant parts; they may also adhere to plant surfaces, if sewage coming from a sewage treatment plant is sprayed over a cultivated field (Franklin et al. 2016). Sulfathiazole, a sulfonamide drug with a strong bacteriostatic activity, showed a high stability in seawater with $18 \%$ degradation within 5 days. It was shown that a seaweed belonging to the class of green algae, sea lettuce (Ulva lactuca $L$.), is able to reduce the concentration of sulfathiazole in water through effective accumulation of the drug. Sulfathiazole inhibited slightly the growth of the sea lettuce after a 96-h exposure.

The mechanism of detoxification of the green alga in question permits to take advantage of the species for bioindication in the environmental risk assessment, whereas from an ecological viewpoint, it shows the potential for sulfathiazole bioaccumulation, which, with the role of macroalga as the main producer in the trophic network, poses a risk of biomagnification (Leston et al. 2014).

\subsection{Uptake of Pharmaceuticals by Plants}

Wu et al. (2010) checked the uptake of three pharmaceuticals (carbamazepine, diphenhydramine and fluoxetine) and two personal care products (triclosan and triclocarban), by an important agricultural speciessoybean (Glycine max Merr.), under greenhouse conditions. After a growth period of 60 and 110 days, the soil and plant tissues were analysed for the content of the above compounds. The study results demonstrated that carbamazepine, triclosan and triclocarban were accumulated in the root tissues and in the aerial plant parts, including seeds. In turn, the accumulation and transport of diphenhydramine and fluoxetine to the aerial plant parts were limited. Degradation is the main mechanism of the breakdown of selected compounds in sewage sludge introduced into soils, whereas plant cultivation on these soils did not have any significant impact on this degradation.

Winker et al. (2010) investigated the process of carbamazepine and ibuprofen uptake by ryegrass plant, fertilised with urine, or a stream of household wastewater derived from a new sanitary system focused on decentralised treatment (Winker et al. 2009). The urine is a potential alternative fertiliser to be used in agriculture; however, its application for fertilising purposes is associated with a risk of spreading pharmaceutical residues in the arable soils. The individual and combined behaviour of carbamazepine and ibuprofen was examined by GC/MS gas chromatography in a greenhouse experiment using ryegrass fertilised with the pharmaceutical spiked urine. Carbamazepine was the only substance that could be detected in the soil, roots and aboveground parts of plants. Only 53\% of carbamazepine, originally present in the fertiliser, was recovered from soil samples taken after 3 months. About $34 \%$ of carbamazepine was recovered from the aboveground plant parts, and $0.3 \%$ from plant roots.

Model calculations showed that neither roots nor Casparian strips posed a significant barrier during the uptake of the compounds tested. The transport of carbamazepine in the plant was clearly linked with transpiration. No ibuprofen was detected in soil or plant parts after a lapse of 3 months following its application, presumably due to its biodegradation. Carbamazepine and ibuprofen both individually and in combination did not have any negative impact on the growth of ryegrass. The effect of transpiration on the accumulation of pharmaceuticals in plants is confirmed by the results of studies using treated wastewater for irrigating agricultural soils in arid and hot climates, where intensive transpiration is observed, which may affect the accumulation of pharmaceuticals in plants. Dodgen et al. (2015) conducted a laboratory study in which three plants were grown, including carrots, lettuce and potatoes. The plants were watered with a solution containing pharmaceuticals, under both cold-moist and hot-dry conditions. The results of the study have shown that transpiration can play a significant role in the process of absorption and transport of pharmaceuticals in plants. This phenomenon can be important in dry and hot climates, where treated wastewater is commonly used for irrigation.

It was shown that vegetable crops irrigated with treated wastewater were able to absorb pharmaceuticals in their edible parts, at the concentration level of $\mathrm{ng} / \mathrm{g}$, regardless of the soil moisture reduction schemes established in the study, and different levels of pharmaceutical concentrations applied. Accumulation of pharmaceuticals (atenolol, diclofenac and ofloxacin) in plants can be attributed to the transpiration process. Ofloxacin was detected at the highest concentrations, followed by atenolol and diclofenac, which were not 
detected in all of the plant tissues tested. Pharmaceuticals were also present in the roots of plants growing on the soil previously irrigated, within the framework of an experiment, with pharmaceutical spiked water (Santiago et al. 2016).

In the literature, there are few publications on the impact of pharmaceuticals on the development of plants. Carter et al. (2015) examined the effect of the presence of carbamazepine and verapamil (at a concentration of $0.005-10 \mathrm{mg} / \mathrm{kg}$ ) on a series of plant responses, using squash (Cucurbita pepo) as an example. The uptake of the above substances increased depending on the dose of the pharmaceutical.

The maximum concentrations of carbamazepine and verapamil in the leaves were 821.9 and $2.2 \mathrm{mg} / \mathrm{kg}$, respectively. At the soil concentration of $>4 \mathrm{mg} / \mathrm{kg}$ of these compounds, the mature plant leaves showed burnt edges, the presence of white spots and the reduction of photosynthetic pigments. No such symptoms were observed during the absorption of verapamil by squash. The carbamazepine uptake was also examined (added in the experiment at a typical concentration occurring in wastewater, i.e. $1 \mu \mathrm{g} / \mathrm{l}$ ) in cucumber (Cucumis sativus $L$., $c v$. Safi), growing in the hydroponic culture and in the greenhouse experiment. The greenhouse experiment was carried out with various types of soil watered with fresh water and reused water after wastewater treatment. The results obtained from the hydroponic cultivation suggest that carbamazepine transport occurs mainly through the mass flow of water, and thus, its highest concentrations and accumulation can be observed in mature, older leaves.

The concentration of carbamazepine in fruit of and leaves of cucumber was negatively correlated with the content of organic matter in the soil. The carbamazepine concentration in the roots and stems was relatively low whereas most of the carbamazepine was recovered from cucumber leaves (76-84\%). The bioaccumulation factor (calculated as the ratio of carbamazepine concentration in a plant to its concentration in soil solution) was $0.8-1$ in cucumber fruit, and was much higher in the leaves (17-20) (Shenker et al. 2011b).

Pharmaceuticals uptake from the soil and their accumulation in edible plant parts was analysed on the example of two drugs: $17 \alpha$-ethinylestradiol and triclosan and cultivated bean (Phaseolus vulgaris), grown on sand and in the soil. The uptake and accumulation of $17 \alpha$-ethinylestradiol and triclosan in plants grown in sand was higher than in plants growing in the soil. In plants grown on sand, the bioconcentration factors (BCF) for $17 \alpha$-ethinylestradiol and triclosan (BCF the concentration of a drug $(\mu \mathrm{g} / \mathrm{g})$ in plant dry matter divided by concentration $(\mu \mathrm{g} / \mathrm{g})$ in dry sand or soil) calculated for roots were 1424 and 16,364, respectively, and for leaves 55 and 85 , respectively. On the other hand, in plants cultivated on the soil, the BCF for $17 \alpha$ ethinyl estradiol decreased from 154 in the first week to 32 in the fourth week, while in the leaves ranged from 18 to 20 (for triclosan 12 in the roots, and 8 in the leaves). The results indicate that the uptake and accumulation of pharmaceuticals occurs in plants, which should be taken into account especially when irrigating fields with wastewater from municipal wastewater treatment plants (Karnjanapiboonwong et al. 2011). Little is known regarding the behaviour and accumulation of pharmaceuticals, including antibiotics, in the edible plant parts and their entry into the human food chain. The transfer of a commonly used veterinary antibiotic, oxytetracycline, from swine manure to aquatic plants was studied in Thailand. The relative bioconcentration of oxytetracycline was measured using three different aquatic plants: watermeal (Wolffia globosa Hartog and Plas), cabomba (Cabomba caroliniana) and water spinach (Ipomoea aquatica Forsk). Watermeal and water spinach are widely consumed in South Asia. The results show that under certain conditions (plants growing for 15 days in undiluted swine manure effluent and an initial oxytetracycline concentration of $43 \mathrm{mg} / \mathrm{kg}$ dry weight) this pathway may account for a significant proportion $(>48 \%)$ of the acceptable daily intake for oxytetracycline (Boonsaner and Hawker 2015).

A study was carried out on the uptake of tetracycline and its metabolites by common reed (Phragmites australis), growing at the Hinsor stream (Turkey), contaminated with sewage from a nearby poultry slaughterhouse. Accumulation of tetracycline and its metabolites in the analysed plant parts decreased in the following order: root $>$ stem $>$ leaves. The concentrations of the tested pharmaceuticals in the plant roots, shoots and leaves were greater for the tetracycline metabolites than for tetracycline itself. The concentrations in water were within the limits of $2.37-21.3 \mu \mathrm{g} / \mathrm{L}$, and in the sediments of the stream in the range of 9.69-27.0 ppb (Arslan Topal 2015).

Research by Sallach et al. (2016) demonstrated the possibility of antibiotics uptake by plants grown for consumption purposes on soils irrigated with pharmaceutical spiked water. Four substances were tested, 
which represented four different classes of antibiotics, including ciprofloxacin, lincomycin, oxytetracycline and sulfamethoxazole. In the tested lettuce samples (Lactuca sativa L.), only lincomycin and sulfamethoxazole were detected at concentrations as high as $1757 \mathrm{ng} /$ $\mathrm{g}$ and $425 \mathrm{ng} / \mathrm{g}$, with a detection limit of $57 \mathrm{ng} / \mathrm{g}$ and $35 \mathrm{ng} / \mathrm{g}$, respectively. The cell lysis method, consisting of freezing and thawing, provided the highest level of extraction efficiency from environmental samples, with a small amount of material for sample analysis, while providing adequate detection limits and analytes recovery reproducibility (Sallach et al. 2016).

Dodgen et al. (2013) evaluated the possibility of uptake and accumulation of four selected pharmaceutical substances and endocrine disrupters, including bisphenol A, diclofenac, naproxen and 4 - nonylphenol by lettuce (Lactuca sativa) and cabbage (Brassica oleracea) in the hydroponic culture. In both plant species, the accumulation process was most intensive for bisphenol A, followed by 4-nonylphenol, diclofenac and naproxen. It was also shown that the accumulation in the roots was much higher than in the leaves and stems. The concentration of pharmaceutical substances and endocrine disorders in plant tissues ranged from $0.22 \pm 0.03$ to $927 \pm 213 \mathrm{ng} / \mathrm{g}$; however, most of the residue was non-extractable. The human exposure to residues of these compounds was considered to be insignificant. In Great Britain, an experiment was carried out to examine the effect of exposure of lettuce (Lactuca sativa) and common radish (Raphanus sativus) to selected non-steroidal anti-inflammatory drugs (at concentrations relevant for the natural environment) (Schmidt and Redshaw 2015). The ability of uptake of tetracycline and amoxicillin was studied under laboratory conditions using common carrot (Daucus carota L.) and lettuce (Lactuca sativa L.). These two plants were grown on the two types of soil from Ghana, watered with antibiotic spiked water, in various fixed concentrations $(0.1-15 \mathrm{mg} / \mathrm{l})$. Tetracycline was determined in all plant samples at the concentration of 4.4 to $8.3 \mathrm{ng} / \mathrm{g}$ in lettuce and from 12 to $36.8 \mathrm{ng} / \mathrm{g}$ fresh weight in carrot. The content of amoxicillin in the tested plant samples ranged from 13.7 to $45.2 \mathrm{ng} / \mathrm{g}$. The average concentration of amoxicillin $(27.1 \mathrm{ng} / \mathrm{g})$ in all samples tested was higher than that of tetracycline $(20.2 \mathrm{ng} / \mathrm{g})$, indicating a more efficient plant uptake of amoxicillin than of tetracycline (Azanu et al. 2016).

Hurtado et al. (2017) also investigated the process of uptake and accumulation of pharmaceuticals and other organic pollutants by plants, using lettuce (Lactuca sativa L.) as the indicator plant. Additionally, biochar was added to the soils to improve their properties. The study results demonstrate that lettuce is capable of taking up and accumulating many pharmaceuticals and organic pollutants. The test substances were determined in lettuce leaves, which are edible parts of the plant. The biochar, improving soil properties, proved to be an effective sorbent for the majority of the organic substances tested. The contents of the tested compounds in the roots and leaves decreased, on the average, by $34-48 \%$ in the roots and by $23-55 \%$ in the leaves after the introduction of biocarbon in the amount of 2.5 and $5 \%$. Therefore, the introduction of biochar into the soil reduced the bioavailability of pharmaceuticals for plants. These results are confirmed by Rajapaksha et al. (2014). The process was examined of sulfamethazine uptake by lettuce (Lactuca sativa L.), cultivated on the soil enriched with biochar obtained from an invasive plant-burr cucumbers (Sicyos angulatus). The lettuce was harvested after 5 weeks of cultivation and the concentration of sulfamethazine was determined. It was observed that in lettuce grown on the soil enriched with biochar, the amount of sulfamethazine uptake was reduced. The introduction of biochar to the soil increased the adsorption of the antibiotic on its surface and restricted the bioavailability of sulfamethazine (Rajapaksha et al. 2014).

Zhang et al. (2012) studied the uptake and accumulation of diclofenac by the macrophytes such as bulrush Scirpus validus. The results prove that diclofenac can be accumulated by plants within the range of 0.17 to $1.49 \mu \mathrm{g} / \mathrm{g}$ (fresh weight) in the roots and $0.13-0.49 \mu \mathrm{g} / \mathrm{g}$ (fresh weight) in the shoots. The fact that diclofenac was detected in the shoots indicates that it can be further transferred to other parts of the plant. In addition, studies have shown that diclofenac passes slowly from the roots to the aerial plant parts, due to its high hydrophobicity. At the same time, these studies have shown that aquatic plants may directly contribute to reducing the content of organic pollutants in wetlands, and that phytoremediation can be a way to remove some of active substances of pharmaceuticals from the environment. Diclofenac and dexamethasone cause oxidative stress and decrease testosterone level. Therefore, these pharmaceuticals can have a negative effect on aquatic organisms (Guiloski et al. 2015). 


\section{Phytoremediation of Pharmaceutical Spiked Wastewater with the Use of Aquatic Organisms}

The presence of pharmaceuticals and endocrinedisrupting substances (EDCs) in effluents from wastewater treatment plants raises significant concerns due to the negative impact these substances may have on human health and entire ecosystems. Considering the pervasiveness of the problem, tests were conducted to assess the ability of two aquatic plants (Lemna sp. and Spirogyra sp.), commonly occurring in the polishing ponds of the biological wastewater treatment plant, to remove six pharmaceutical substances (diclofenac, acetaminophen, ibuprofen, carbamazepine, clofibric acid and propranolol) under laboratory conditions. Treated wastewater and water of the highest purity were supplied to plant containing and non-plant reactors. The study was conducted under cover or without a cover. The highest removal efficiency, which was from 31 to $100 \%$, was achieved in uncovered plant systems containing treated sewage after 20 days of incubation. The results indicate that the presence of plants in biological ponds plays an important role in the removal of pharmaceuticals from wastewater (Garcia-Rodríguez et al. 2015).

Metformin, the active substance of an antidiabetic drug, was detected at high concentrations in sewage sludge and treated wastewater. The study on absorption and transport was carried out to evaluate and identify the final fate of metformin in the phytoremediation process, using an aquatic plantcommon cattail (Typha latifolia). After 28 days, the metformin removal efficiency was in the range of 74 $\pm 4.1-81.1 \pm 3.3 \%$. The metformin content in the roots increased during the first 2 weeks of the experiment, and then significantly decreased. In contrast to the above, the metformin concentration in leaves and rhizomes increased systematically. The bioaccumulation of metformin in the roots was much higher than in the leaves and rhizomes. One of the metformin degradation products, methyl biguanide, has been identified in common cattail, whereas the other, guanylurea, has not been detected, which means that it has undergone a rapid biodegradation with the participation of plant enzymes. The above results may contribute to understanding and assessing the potential of phytoremediation method in the process of removing pharmaceuticals from wastewater (Cui and Schröder 2016).

\section{Conclusion}

International institutions predict that the consumption of drugs in the coming years will increase due to a wider access to cheaper medicines, including the generic ones. It is estimated that many more active pharmaceutical substances are released into the environment due to the use of veterinary medicines than due to medicines intended for humans. From an environmental viewpoint, one should also bear in mind multiple problems that have not been solved so far, in particular those concerning residues of active pharmaceutical substances in the respective environmental compartments (soil, water, plants) and, consequently, in food produced in areas that are irrigated with treated or partly treated or untreated wastewater, where sewage sludge and natural fertilisers are introduced to fertilise soils. Certain amounts of pharmaceuticals may accumulate in the soil and penetrate the trophic chain passing from plants to humans. Sewage used for irrigation is currently not covered by any chemical standards, including environmental risk assessment. The active substances of drugs can be degraded during biological wastewater treatment as well as in water reservoirs, in the soil and during abiotic reactions. These processes partially reduce the potentially harmful effects of drugs, however, some breakdown products have similar toxicity as their parent substance.

The fate and behaviour of pharmaceutical residues in soils depends on the intensity of their sorption on the solid soil particles, including organic matter. The strength of sorption affects the bioavailability of the medicines' active substances and their persistence in the soil environment. In plants grown on sandy soils, the uptake and accumulation of pharmaceuticals will be much more intense than in soils with a higher content of silt particles and organic matter. This principle should be taken into account when irrigating arable soils with wastewater from municipal wastewater treatment plants and using either sewage sludge or natural fertilisers (manure, slurry) for fertilisation. Calculated bioconcentration factors (BCF) for some active substances of pharmaceuticals in plant roots can reach even 16,364 , while in the leaves they are significantly lower, attaining maximally 85 .

There is little information on the bioaccumulation of pharmaceuticals in organisms and in the trophic chain, and the effect of antibiotics found in the soil solution on higher organisms has not so far been discussed in the 
literature. The presented state of knowledge suggests that studies on the accumulation of pharmaceuticals, including antibiotics, in edible plant parts and their entry into the human food chain should be continued to identify the health risks for people who are consumers of these plants.

Code Availability Not applicable.

Authors' Contributions General concept: BG

Data collection: $\mathrm{BG}, \mathrm{MK}, \mathrm{JW}, \mathrm{MG}$

Review writing: $\mathrm{BG}, \mathrm{MK}, \mathrm{JW}, \mathrm{MG}$

Data Availability Not applicable.

\section{Compliance with Ethical Standards}

Conflict of Interest The authors declare that they have no conflict of interest.

\section{Ethics Approval Not applicable.}

Consent for Publication All authors have approved the manuscript.

Open Access This article is licensed under a Creative Commons Attribution 4.0 International License, which permits use, sharing, adaptation, distribution and reproduction in any medium or format, as long as you give appropriate credit to the original author(s) and the source, provide a link to the Creative Commons licence, and indicate if changes were made. The images or other third party material in this article are included in the article's Creative Commons licence, unless indicated otherwise in a credit line to the material. If material is not included in the article's Creative Commons licence and your intended use is not permitted by statutory regulation or exceeds the permitted use, you will need to obtain permission directly from the copyright holder. To view a copy of this licence, visit http://creativecommons.org/licenses/by/4.0/.

\section{References}

Alexy, R. (2001). What do we know about antibiotics in the environment? In K. Kummerer (Ed.), Pharmaceuticals in the environment (pp. 209-221). New Jork: Springer.

Al-Farsi, R. S., Ahmed, M., Al-Busaidi, A., \& Choudri, B. S. (2017). Translocation of pharmaceuticals and personal care products (PPCPs)into plant tissues: a review. Emerging Contaminants, 3, 132-137.

Arslan Topal, E. I. (2015). Uptake of tetracycline and metabolites in Phragmites australis exposed to treated poultry slaughterhouse wastewaters. Ecological Engineering, 83, 233-238.
Azanu, D., Mortey, C., Darko, G., Weisser, J. J., Stryrishave, B., \& Abaidoo, C. (2016). Uptake of antibiotics from irrigation water by plants. Chemosphere, 157, 107-114.

Balizs, G., \& Hewitt, A. (2003). Determination of veterinary drug residues by liquid chromatography and tandem mass spectrometry. Analytica Chimica Acta, 492, 105-131.

Biel-Maeso, M., Corada-Fernandez, C., \& Lara-Martin, P. A. (2018). Monitoring the occurrence of pharmaceuticals in soils irrigated with reclaimed wastewater. Environmental Pollution, 235, 312-321.

Boonsaner, M., \& Hawker, D. W. (2015). Transfer of oxytetracycline from swine manure to three different aquatic plants: implications for human exposure. Chemosphere, 122, 176182.

Borgman, O., \& Chefetz, B. (2013). Combined effects of biosolids application and irrigation with reclaimed wastewater on transport of pharmaceutical compounds in arable soils. Water Research, 47, 3431-3443.

Botsoglou, N. A. (2001). Drug residues in foods: pharmacology, food safety, and analysis. Copyright (C) 2000. New York: Marcel Dekker, Inc. All Rights Reserved.

Boxall, A. B. A. (2004). The environmental side effects of medication. How are human and veterinary medicines in soils and water bodies affecting human and environmental health? EMBO Reports, 5, 1110-1116.

Boxall, A., Johnson, P., Smith, E. J., Sinclair, C. J., Stutt, E., \& Levy, L. (2006). Uptake of veterinary medicines from soils into plants. Journal of Agricultural and Food Chemistry, 54(6), 2288-2297.

Calderon-Preciado, D., Jimenez-Cartagena, C., Matamoros, V., \& Bayona, J. M. (2011). Screening of 47 organic microcontaminants in agricultural irrigation waters and their soil loading. Water Research, 45, 221-231.

Carr, D. L., Morse, A. N., Zak, J. C., \& Anderson, T. A. (2011). Biological degradation of common pharmaceuticals and personal care products in soils with high water content. Water, Air, and Soil Pollution, 217, 127-134.

Carter, L. J., Williams, M., Böttcher, C., \& Kookana, R. S. (2015). Uptake of pharmaceuticals influences plant development and affects nutrient and hormone homeostases. Environmental Science \& Technology, 49, 12509-12518.

Carvalho, P. N., Basto, M. C. P., Almeida, C. M. R., \& Brix, H. (2014). A review of plant-pharmaceutical interactions: from uptake and effects in crop plants to phytoremediation in constructed wetlands. Environmental Science and Pollution Research, 21, 11729-11763.

Chen, F., Ying, G., Kong, L. X., Wang, L., Zhao, J., \& Zhou, L. J. (2011). Distribution and accululation of endocrine-disrupting chemicals and pharmaceuticals in wastewater irrigated soils in Hebei. China Environmental Pollution, 159, 1490-1498.

Cleuvers, M. (2004). Mixture toxicity of the anti-inflammatory drugs diclofenac, ibuprofen, naproxen, and acetylsalicylic acid. Ecotoxicology and Environmental Safety, 59, 309-315.

Cui, H., \& Schröder, P. (2016). Uptake, translocation and possible biodegradation of the antidiabetic agent metformin by hydroponically grown Typha latifolia. Journal of Hazardous Materials, 308, 355-361.

Czech, B. (2012). Usuwanie farmaceutyków z wód i ścieków z wykorzystaniem metod adsorpcyjnych i fotokatalitycznych. In J. Ryczkowski (Ed.), Absorbenty i Katalizatory. Wybrane 
Technologie a Środowisko (pp. 443-452). Rzeszów: Uniwersytet Rzeszowski.

Dalkmann, P., Siebe, C., Amelung, W., Schloter, M., \& Siemens, J. (2014). Does long-term irrigation with untreated wastewater accelerate the dissipation of pharmaceuticals in soil? Environmental Sciences, 48, 4963-4970.

Davis, J. G., Truman, C. C., Kim, S. C., Ascough, J. C., \& Carlson, K. (2006). Antibiotic transport via runoff and soil loss. Journal of Environmental Quality, 35, 2250-2260.

Deloitte, INERIS, Klaus Kümmerer, LSE, Milieu Ltd, 2015. Options for a strategic approach to pharmaceuticals in the environment - Task 1 Report. https://ec.europa. eu/info/sites/info/files/study_report_public_consultation pharmaceuticals_environment.pdf

Deloitte Sustainability Background document for public consultation on pharmaceuticals in the environment In partnership with Milieu Ltd, Ineris and Pr. Klaus Kümmerer (2017) Interim report for European Commission contract number: 07.0201/2015/721866/SER/ENV.C.1. https://ec.europa. $\mathrm{eu} / \mathrm{info} / \mathrm{sites} / \mathrm{info} / \mathrm{files} /$ background_document_public consultation_pharmaceuticals_environment.pdf

Dodgen, L. K., Li, J., Parker, D., \& Gan, J. J. (2013). Uptake and accumulation of four PPCP/EDCs in two leafy vegetables. Environmental Pollution, 182, 150-156.

Dodgen, L. K., Ueda, A., Wu, X., Parker, D. R., \& Gan, J. (2015). Effect of transpiration on plant accumulation and translocation of PPCP/EDCs. Environmental Pollution, 198, 144153.

Doruk, A. Y., Goker, H., \& Cihangir, N. (2018). Biodegradation of diclofenac with fungal strains. Archives of Environment Protect, 44(1), 55-62.

Drillia, P., Stamatelatou, K., \& Lyberatos, G. (2005). Fate and mobility of pharmaceuticals in solid matrices. Chemosphere, 60, 1034-1044.

Eggen, T., Asp, T. N., Grave, K., \& Hormazabal, V. (2011). Uptake and translocation of metformin, ciprofloxacin and narasin in forage- and crop plants. Chemosphere, 85, 26-33.

Fatta-kassinos, D., Vasquez, M. I., Kummerer, K. (2011). Transformation products of pharmaceuticals in surface waters and wastewater formed during photolysis and advanced oxidation processes - Degradation, elucidation of byproducts and assessment of their biological potency. Chemosphere 85, 693-709

Fent, K., Weston, A., \& Caminada, D. (2006). Ecotoxicology of human pharmaceuticals. Aquatic Toxicology, 76, 122-159.

Franklin, A. M., Williams, C. F., Andrews, D. M., Woodward, E. E., \& Watson, J. E. (2016). Uptake of three antibiotics and an antiepileptic drug by wheat crops spray irrigated with wastewater treatment plant effluent. Journal of Environmental Quality, 45, 546-554.

Garcia-Rodríguez, A., Matamoros, V., Fontás, C., \& Salvadó, V. (2015). The influence of Lemna sp. and Spirogyra sp. on the removal of pharmaceuticals and endocrine disruptors in treated wastewaters. International Journal of Environmental Science and Technology, 12, 2327-2338.

Giger, W., Alder, A., Golet, E., Kohler, H., McArdell, C., Molnar, E., \& Siegrist, H. (2003). Occurrence and fate of antibiotics as trace contaminants in wastewaters, sewage sludges, and surface waters. Chimica International Journal of Chemistry, $57,485-491$.
Graham, D. W. (2016). Appearance of $\beta$-lactam resistance genes in agricultural soils and clinical isolates over the 20th century. Nature, 6, 1-6.

Grassi, M., Rizzo, L., \& Farina, A. (2013). Endocrine disruptors compounds, pharmaceuticals and personal care products in urban wastewater: implications for agricultural reuse and their removal by adsorption process. Environmental Science and Pollution Research, 20, 3616-3628.

Grossberger, A., Hadar, Y., Borch, T., \& Chefetz, B. (2014). Biodegradability of pharmaceutical compounds in agricultural soils irrigated with treated wastewater. Environmental Pollution, 185, 168-177.

Guiloski, I. C., Coelho Ribas, J. L., Pereira, L., Perbiche Neves, A. P., \& Assis, C. S. (2015). Effects of trophic exposure to dexamethasone and diclofenac in freshwater fish. Ecotoxicology and Environmental Safety, 114, 204-211.

Gworek, B., Kijeńska, M., Zaborowska, M., Wrzosek, J., Tokarz, L., \& Chmielewski, J. (2020). Occurence of pharmaceuticals in aquatic environment - a review. Desalination and Water Treatment, 184, 375-387.

Gworek, B., Kijeńska, M., Zaborowska, M., Wrzosek, J., Tokarz, L., \& Chmielewski, J. (2019). Pharmaceuticals in aquatic environment. Fate and behaviour, ecotoxicology and risk assessment - a review. Acta Poloniae Pharmaceutica, 76(3), 397-407.

Halling-Sørensen, B., Nors, N. S., Lanzky, P., Ingerslev, F., Holten, L. H., \& Jørgensen, S. (1998). Occurrence, fate and effects of pharmaceutical substances in the environment- a review. Chemosphere, 36, 357-393.

Halling-Sörensen, B., Sengelöv, G., \& Tjörnelund, J. (2002). Toxicity of tetracyclines and tetracycline degradation products to environmentally relevant bacteria, including selected tetracycline-resistant bacteria. Archives of Environmental Contamination and Toxicology, 42, 263-271.

Hamscher, G., Kuhne, M., Korner, U., Schedl, D., \& Wenzel, S. (2001). Formation of anhydrotetracycline during a hightemperature treatment of animal-derived feed contaminated with tetracycline. Food Chemistry, 75, 423-429.

Hartmann, A. (2013). Occurrence of CTX-M producing Escherichia coli in soils, cattle, and farm environment in France (Burgundyregion). Frontiers in Microbiology, 3, 1-7.

Heberer, T. (2002). Occurrence, fate, and removal of pharmaceutical residues in the aquatic environment: a review of recent research data. Toxicology Letters, 131, 5-17.

Heuer, H. (2011). Antibiotic resistance gene spread due to manure application on agricultural fields. Current Opinion in Microbiology, 14, 236-243.

Ho, Y. B., Zakaria, M. P., Latif, P. A., \& Saari, N. (2012). Simultaneous determination of veterinary antibiotics and hormone in broiler manure, soil and manure compost by liquid chromatography - tandem mass spectrometry. Journal of Chromatography. A, 1262, 160-168.

Hurtado, C., Cañameras, N., Domínguez, C., Price, G. W., Comas, J., \& Bayona, J. M. (2017). Effect of soil biochar concentration on the mitigation of emerging organic contaminant uptake in lettuce. Journal of Hazardous Materials, 323, 386393.

Jałowiecki, Ł., Płaza, G., Ejhed, H., \& Nawrotek, M. (2019). Aerobic biodegradation of norfloxacin and ofloxacin by a microbial consortium. Archives of Environment Protect, 45(4), 40-47. 
Jjemba, P. K. (2006). Excretion and ecotoxicity of pharmaceutical and personal care products in the environment. Ecotoxicology and Environmental Safety, 63, 113-130.

Karnjanapiboonwong, A., Chase, D. A., Cañas, J. E., Jackson, W. A., Maul, J. D., Morse, A. N., \& Anderson, T. A. (2011). Uptake of $17 \alpha$-ethynylestradiol and triclosan in pinto bean, Phaseolus vulgaris. Ecotoxicology and Environmental Safety, 74, 1336-1342.

Katipoglu-Yazan, T., Merlin, C., Pons, M.-N., Ubay Cokgor, E., \& Orhon, D. (2015). Chronic impact of tetracycline on nitrification kinetics and the activity of enriched nitrifying microbial culture. Water Research, 72, 227-238.

Kemper, M. (2008). Veterinary antibiotics in the aquatic and terrestrial environment. Ecological Indicators, 8, 1-13.

Kinney, C. A., Furlong, E. T., Werner, S. L., \& Cahill, J. D. (2006). Presence and distribution of wastewater-derived pharmaceuticals in soil irrigated with reclaimed water. Environmental Toxicology and Chemistry, 25, 317-326.

Kodešová, R., Kočárek, M., Klement, A., Golovko, O., Koba, O., Fér, M., Nikodem, A., Vondráčková, L., Jakšik, O., \& Grabic, R. (2016). An analysis of the dissipation of pharmaceuticals under thirteen different soil conditions. Science of the Total Environment, 544, 369-381.

Kumar, K., Gupta, S. C., Baidoo, S. K., Chander, Y., \& Rosen, C. J. (2005). Antibiotic uptake by plants from soil fertilized with animal manure. Journal of Environmental Quality, 34, 20822085.

Kümmerer, K. (2001). Pharmaceuticals in the environment: sources, fate, effects and risks. Berlin: Springer.

Kümmerer, K. (2004). Pharmaceuticals in the environmentsources, fate, effects and risks. Berlin, Heidelberg: Springer.

Kümmerer, K. (2009). Antibiotics in the aquatic environment - a review - part I. Chemosphere, 75, 417-434.

Lees, K., Fitzsimons, M., Snape, J., Tappin, A., \& Comber, S. (2016). Pharmaceuticals in soils of lower income countries: physico-chemical fate and risks from wastewater irrigation. Environment International, 94, 712-723.

Leston, S., Nunes, M., Viegas, I., Nebot, C., Cepeda, A., Pardal, M. Â., \& Ramos, F. (2014). The influence of sulfathiazole on the macroalgae Ulva lactuca. Chemosphere, 100, 105-110.

Lin, K., \& Gan, J. (2011). Sorption and degradation of wastewaterassociated non-steroidal anti-inflammatory drugs and antibiotics in soils. Chemosphere, 83, 240-246.

Monteiro, S. C., \& Boxall, A. B. A. (2009). Factors affecting the degradation of pharmaceutical in agricultural soils. Environmental Toxicology and Chemistry, 28, 2546-2554.

Monteiro, S. C., \& Boxall, A. B. A. (2010). Occurrence and fate of human pharmaceuticals in the environment. Reviews of Environmental Contamination and Toxicology, 202, 53-154.

Mrozik, W., \& Stefańska, J. (2014). Adsorption and biodegradation of antidiabetic pharmaceuticals. Chemosphere, 95, 281288.

Nikolaou, A., Meric, S., \& Fatta, D. (2007). Occurrence patterns of pharmaceuticals in water and wastewater environments. Analytical and Bioanalytical Chemistry, 387, 1225-1234.

Nollet, L. M. L. (2004). Handbook of food analysis. New York: Marcel Dekker Inc..

OECD. (2011). "Pharmaceutical expenditure", in Health at a glance 2011: OECD indicators. Paris: OECD Publishing.

Quintiles IMS. (2016). Report by the QuintilesIMS Institute Outlook for global medicines through 2021 balancing cost and value QuintilesIMS Institute 100 IMS Drive. In Outlook for Global Medicines through 2021. USA: Parsippany.

Pal, R., Megharaj, M., Kirkbride, K. I., \& Naidu, R. (2013). Illicit drugs and the environment - a review. Science of the Total Environment, 463-464, 1079-1092. https://doi.org/10.1016 /j.scitotenv.2012.05.086.

Picó, Y., \& Andreu, V. (2007). Fluoroquinolones in soil-risks and challenges. Analytical and Bioanalytical Chemistry, 387, $1287-1299$.

Rajapaksha, A. U., Vithanage, M., Lim, J. E., Ahmed, M. B. M., Zhang, M., Lee, S. S., \& Ok, Y. S. (2014). Invasive plantderived biochar inhibits sulfamethazine uptake by lettuce in soil. Chemosphere, 111, 500-504.

Reemtsma, T., \& Jekel, M. (2006). Organic pollutants in the water cycle. Weinheim: WILEY-VCH.

Sacher, F., Lange, F. T., Brauch, H. J., \& Blankenhorn, I. (2001). Pharmaceuticals in ground waters. Analytical methods and result of a monitoring program in Baden-Wurttemberg, Germany. Journal of Chromatography. A, 938, 199-210.

Salgot, M., Priestley, G. K., \& Folch, M. (2012). Golf course irrigation with reclaimed water in the Mediterranean: a risk management matter. Water, 4, 389-429.

Sallach, J. B., Snow, D., Hodges, L., Li, X., \& Bartelt-Hunt, S. (2016). Development and comparison of four methods for the extraction of antibiotics from a vegetative matrix. Environmental Toxicology and Chemistry, 35, 889-897.

Santiago, S., Roll, D. M., Ray, C., Williams, C., Moravcik, P., \& Knopf, A. (2016). Effects of soil moisture depletion on vegetable crop uptake of pharmaceuticals and personal care products (PPCPs). Environmental Science and Pollution Research, 23, 20257-20268.

Sarmah, K., Meyer, M. T., \& Boxall, A. B. A. (2006). A global perspective on the use, sales, exposure pathways, occurrence, fate and effects of veterinary antibiotics (VAs) in the environment. Chemosphere, 65, 725-759.

Schmidt, W., \& Redshaw, W. C. H. (2015). Evaluation of biological endpoints in crop plants after exposure to non-steroidal anti-inflammatory drugs (NSAIDs): implications for phytotoxicological assessment of novel contaminants. Ecotoxicology and Environmental Safety, 112, 212-222.

Shenker, M., Harush, D., Ben-ari, J., \& Chefetz, B. (2011a). Uptake of carbamazepine by cucumber plants - a case study related to irrigation with reclaimed wastewater. Chemosphere, 82, 905-910.

Shenker, M., Harush, D., Ben-ari, J., \& Chefetz, B. (2011b). Uptake of carbamazepine by cucumber plants - a case study related to irrigation with reclaimed wastewater. Chemosphere, 82, 905-910.

Tang, T., Shi, T., Li, D., Xia, J., Hu, Q., \& Cao, Y. (2012). Adsorption properties and degradation dynamics of endocrine-disrupting chemical levonorgestrel in soils. Journal of Agricultural and Food Chemistry, 60, 3999-4004.

Thiele-Bruhn, S. (2003). Pharmaceutical antibiotic compounds in soils - review. Journal of Plant Nutrition and Soil Science, 166, 145-167.

Winker, M., Clemens, J., Reich, M., Gulyas, H., \& Otterpohl, R. (2010). Ryegrass uptake of carbamazepine and ibuprofen applied by urine fertilization. Science of the Total Environment, 408, 1902-1908.

Winker, M., Vinneras, B., Muskolus, A., Arnold, U., \& Cjemens, J. (2009). Fertiliser products from new sanitation systems: 
their potential values and risks. Bioresource Technology, 100, 4090-4096.

Wu, C., Spongberg, A. L., Witten, J. D., Fang, M., \& Czajkowski, K. P. (2010). Uptake of pharmaceutical and personal care products by soybean plants from soils applied with biosolids and irrigated with contaminated. Environmental Science \& Technology, 44, 6157-6161.

Xu, J., Chen, W., Wu, L., \& Chang, A. C. (2009). Adsorption and degradation of ketoprofen in soils. Journal of Environmental Quality, 38, 1177-1182.

Yang, Y. Y., Gray, J. L., Furlong, E. T., Davis, J. G., Revello, R. C., \& Borch, T. (2012). Steroid hormone runoff from agricultural test plots applied with municipal biosolids. Environmental Science \& Technology, 46, 2746-2754.
Yu, Y., Liu, Y., \& Wu, L. (2013). Sorption and degradation of pharmaceuticals and personal care products (PPCPs) in soils. Environmental Science and Pollution Research, 20, 42614267.

Zhang, D. Q., Hua, T., Gersberg, R. M., Zhu, J., Jern Wun, N. G., \& Tan, S. K. (2012). Fate of diclofenac in wetland mesocosms planted with Scirpus validus. Ecological Engineering, 49, 59-64.

Publisher's Note Springer Nature remains neutral with regard to jurisdictional claims in published maps and institutional affiliations. 